\title{
DE LOS BIENES Y DE SU DOMINIO, POSESIÓN, USO Y GOCE
}

\section{Jaime Alcalde Silva}

Profesor asociado de Derecho Privado

Pontificia Universidad Católica de Chile

LA INSCRIPCIÓN CONSERVATORIA COMO ELEMENTO LEGITIMANTE PARA EL EJERCICIO DE LAS ACCIONES REIVINDICATORIA Y PUBLICIANA LA ACCIÓN PUBLICIANA SOLO PROCEDE A FAVOR DEL POSEEDOR REGULAR, EL CUAL DEBE CONTAR A SU FAVOR CON LA COMPETENTE INSCRIPCIÓN. LA ACCIÓN PUBLICIANA COMO UNA CONSECUENCIA DEL RÉgimen de las COSAS ADOPTADo POR EL Código CIVIL, BASAda EN la PRESUNCión de mejor derecho. Prestaciones mutuas y edificación en Suelo ajeno. La DENunCia de obra NUEVA. La ACCESión INVERTIDA. Corte Suprema, SENTENCIA DE 5 DE JUNIO DE 2018, ROL N. ${ }^{\circ} 35.127-2017$ (CL/JUR/2620/2018)*.

\section{LA CUESTIÓN DISCUTIDA}

El 12 de junio de 2013, Pablo Eduardo Liberato Parra Parada presentó una demanda de reivindicación contra José Manuel Espinoza Becerra ante el Juzgado de Letras de Pichilemu. Ella estaba destinada a que este último fuera condenado a restituir el inmueble situado en calle Vista Hermosa s/n, sector Playa Hermosa, comuna de Pichilemu, con una superficie de $256 \mathrm{~m}^{2}$, que deslinda: al norte, con calle Vista Hermosa en diez metros; al este, con Jorge González, en 25,60 m; al sur, con Mónica González, en diez metros separado por un cerco; y al oste, con terreno de playa que lo separa del mar chileno en $25,60 \mathrm{~m}$.

Fundaba su demanda en que había adquirido dicho bien raíz merced al procedimiento de saneamiento previsto en el DL 2695/1979, que había concluido por resolución de la SEREMI de Bienes Nacionales de la Región del Libertador General Bernardo O'Higgins de 15 de febrero de 2006. Ella constaba inscrita a su nombre a fojas $3, n{ }^{\circ} 3$ del Registro de Propiedad, tomo especial de Bienes Nacionales correspondiente al año 2006, a cargo del Conservador de Bienes Raíces de Pichilemu. Agregaba que dicha regularización se hizo ajustada a derecho y contó con la autorización del anterior poseedor, Pedro Juan Vargas González.

\footnotetext{
${ }^{*}$ Este comentario hace parte del proyecto Fondecyt de Iniciación n. ${ }^{\circ} 11160615$, del cual el autor es investigador responsable.
} 
Precisaba que su posesión (primero material y posteriormente legal) había comenzado el 25 de julio de 2002 y se había visto reflejada en el hecho de tener cercado el predio y confiada su vigilancia a un vecino del sector. Fue este el que le informó que terceros habían removido la alambrada para realizar excavaciones e instalar elementos de construcción en el interior. Advertido de este hecho, concurrió a Pichilemu el 7 de marzo de 2013 y se encontró con trabajadores que iniciaban faenas en su predio por orden del demandado. Pedro Parra Parada, ante la negativa de estos de abandonar la propiedad, concurrió a Carabineros para denunciar la situación.

El 31 de marzo del mismo año volvió al inmueble y constató nuevamente la presencia de trabajadores contratados por el demandado, el cual fue contactado por Carabineros y se comprometió a hacer cesar las obras mientras no se aclarase el derecho que invocaba sobre el predio. Sin embargo, las faenas se reanudaron tan pronto el furgón policial se retiró del lugar.

La demanda añadía que el demandado no era titular de ningún derecho sobre el inmueble, pues sólo argüía una cesión de derechos posesorios de parte de Pedro Juan Vargas González datada en 2009. Tampoco había tenido la posesión material sobre el mismo hasta el 7 de marzo de 2013, cuando comenzaron los trabajos antes referidos, sin que en la Dirección de Obras de la Municipalidad de Pichilemu hubiese constancia de la apertura de un expediente administrativo que autorizase esa construcción.

206 Finalmente, el demandante solicitaba al tribunal que declarase que era dueño exclusivo del inmueble reclamado por haberlo adquirido mediante el procedimiento de saneamiento del DL 2695/1979; que el demandado no tenía derecho alguno sobre el mismo; que este debía restituir el bien raíz dentro de décimo día de ejecutoriada la sentencia; que había de retirar todos los materiales y elementos de construcción existentes al interior; que había de ser condenado al pago de todos los deterioros como poseedor de mala fe y también al de los frutos naturales y civiles conforme a esa misma regla, además de las costas del juicio.

El demandado contestó la demanda, solicitando su rechazo y la condena en costas del actor. Su defensa se sustentaba en el hecho de ser dueño y poseedor tranquilo y pacífico de un inmueble situado en el sector de Playa Hermosa, al final del pasaje Vista Hermosa, de la comuna de Pichilemu, que tiene una superficie aproximada de $1000 \mathrm{~m}^{2}$ y cuyos linderos son los siguientes: al norte, con pasaje Vista Hermosa en 36 m lineales; al sur, con terrenos de Pedro Juan Vargas González, que deslindan con la prolongación del pasaje Santa Mónica en $36 \mathrm{~m}$ lineales; al oriente, con propiedad de Luis Catalán y servidumbre de José González de por medio, en 30 m lineales aproximadamente; y al poniente, con el océano Pacífico. Dicho inmueble fue adquirido en el año 2003 a Pedro Juan Vargas González, a quien pertenecía desde mayo de 1972 por haberlo recibido por transmisión como heredero testamentario de María Inés González Tapia. Como fuere, el 15 de julio de 2009 se otorgó una escritura pública de cesión de "derechos posesorios" para regularizar esa adquisición. 
Declaraba que la entrega material se había producido en el momento de la adquisición del referido inmueble. La posesión sobre este se evidenciaba por una serie de hechos positivos de aquellos a los que solo da derecho el dominio, como: limpieza, movimiento de tierras, rellenos, cercamiento de la propiedad, solicitud e instalación de un arranque de agua potable, plantación de árboles y, desde octubre de 2012, la construcción de una vivienda. Además, a partir del año 2007 el demandado había trabajado en la regularización del pasaje por el que se ingresaba a su propiedad.

En opinión del demandado, la acción reivindicatoria que motivaba el juicio no podía prosperar. Para que así ocurriese, era preciso que el reivindicador fuese dueño de la cosa que reclamaba, lo que no sucedía en la especie. La razón era que, al haberse dirigido la demanda en su contra, el actor le reconocía la calidad de poseedor y, por consiguiente, se encontraba amparado por la presunción dominical del art. 700 II del $C C$. Fuera de eso, objetaba que en el procedimiento de saneamiento se hubiesen observado los requisitos exigidos por el DL 2695/1979, de suerte que el título que invocaba el demandante adolecía de nulidad de derecho público, la cual es absoluta e imprescriptible ${ }^{1}$. A mayor abundamiento, y dado que el demandante nunca había ejercido actos posesorios sobre el inmueble, solo se encontraba amparado por una "inscripción de papel", la que fue obtenida mediante un procedimiento administrativo irregular.

En su defensa alegaba, asimismo, la excepción de la prescripción extintiva de la acción de dominio, puesto que el demandante había perdido la posesión de la cosa y, junto con ello, su dominio, extinguiéndose consecuencialmente toda acción destinada a reclamar ese derecho (art. 2317 del CC).

Para el caso de que el tribunal acogiese la acción reivindicatoria, el demandado alegaba encontrarse de buena fe, por lo que tenía derecho a que le fuesen abonadas las mejoras útiles hechas antes de contestar la demanda y que habían aumentado el valor venal del bien. Invocaba a su favor, el art. 669 del $C C$, que permite recobrar el valor del edificio, plantación o sementera hecha a ciencia y paciencia del dueño del terreno. Para garantizar el pago de esas prestaciones, solicitaba al tribunal que declarase a su favor el derecho legal de retención previsto en el art. 914 del $C C$.

Sobre la base de la argumentación precedente, el demandado pedía al tribunal que rechazase la demanda en todas sus partes; que se acogiese la excepción de prescripción; que se le declarase como dueño del predio reivindicado, procediéndose a las inscripciones y cancelaciones conservatorias que fuera del caso; y que se condenase en costas al actor. Para el evento de que la demanda no fuese desechada, pedía que se lo tuviera como poseedor de buena

\footnotetext{
${ }^{1}$ Sobre la nulidad de derecho público se ha discutido bastante. El demandado parece recurrir a la teoría expuesta por el profesor Eduardo Soto Kloss, que concibe que esta clase de nulidad opera ab initio e ipso iure y es insanable e imprescriptible. Véase un resumen de la discusión en Agüero (2017).
} 
fe y se reconociese a su favor el derecho legal de retención sobre el inmueble hasta el completo pago de los rubros que le correspondían.

De forma subsidiaria, José Manuel Espinoza Becerra interpuso como demanda reconvencional la acción publiciana del art. 894 del $C C$, para la cual reiteraba los fundamentos de hecho y de derecho expuestos en su contestación. Por ella solicitaba al tribunal que se declarase que Eduardo Parra Parada había turbado su posesión; que la propiedad en disputa le pertenecía única y exclusivamente, debiendo practicarse las inscripciones correspondientes para garantizarla; que el actor y demandado reconvencional debían cesar de inmediato en la turbación y amenaza que estaba provocando; y que debía pagar las costas del juicio.

$\mathrm{Al}$ evacuar la réplica, el actor reiteró los argumentos vertidos en su demanda, pero agregó algunas consideraciones respecto de la excepción de prescripción alegada por el demandado. En su opinión, lo sostenido a su respecto comportaba un error jurídico, porque la prescripción solo es admisible como acción, vale decir, ella debe ser demandada directamente o por vía de reconvención por el poseedor que quiere valerse de ese modo de adquirir. Además, el causante del demandado había cedido sus "derechos posesorios" en el año 2002 al reivindicador, previa autorización y renuncia de Pedro Juan Vargas González, situación que dicha parte debía conocer por su calidad de asesor de este último. Por si esto no fuera suficiente, los terrenos sobre los que el demandado pretendía tener posesión y sobre los cuales se habría verificado a su favor la prescripción adquisitiva tenían en realidad el carácter de playa (art. 594 del $C C$ ) y, por consiguiente, revestían la calidad de un bien nacional de uso público (art. 589 del $C C$ ).

Respecto de la demanda reconvencional, Pedro Parra Parada agregaba que la posesión de los bienes raíces se adquiere, conserva y prueba por la respectiva inscripción conservatoria, de la cual carecía el demandado, por lo que la acción publiciana ejercida debía ser rechazada por falta de legitimación activa. Por el contrario, a su favor sí existía la competente inscripción procedente de la resolución de saneamiento dictada por la Seremi de Bienes Nacionales de la Región del Libertador Bernardo O'Higgins, la cual lo había convertido en dueño y poseedor de dicho inmueble. Por eso, la demanda reconvencional había de ser rechazada, con costas.

En su dúplica, el demandado insistía que el actor no tenía la posesión material y legal del bien raíz reclamado, puesto que él lo había adquirido en 2003 y, posteriormente, regularizó esa adquisición mediante la escritura pública de cesión de derechos posesorios suscrita en 2009, fuera de que merced a su demanda le reconocía la calidad de poseedor. Siendo así, no era efectivo que careciese de título; cuanto más, se podía decir que su título era fraudulento y, en cualquier caso, había estado acompañado de una posesión ininterrumpida, tanto por su parte como por su antecesor. Tampoco era verdad que su predio fuese una playa.

En la dúplica a la demanda reconvencional, el demandante volvía sobre la prueba de la posesión establecida en los arts. 924 y 925 del $C C$. El primero 
de ellos cedía a su favor, por gozar de una inscripción conservatoria relativa al predio cuya reivindicación solicitaba. El segundo no podía beneficiar al demandado, dado que este ingresó con violencia y clandestinidad al predio, comenzando las obras de construcción relatadas en la demanda principal. El único título que podía alegar en su defensa era la escritura pública suscrita junto a Pedro Vargas González, quien ya le había cedido los derechos. Distinta era su situación, puesto que él había regularizado y adquirido por prescripción el inmueble objeto del juicio de acuerdo con las reglas del DL 2695/1979.

El Juzgado de Letra de Pichilemu dictó sentencia de primer grado el 18 de noviembre de 2015. En ella se acogió la demanda de reivindicación y se ordenó al demandado que restituyese el inmueble de $256 \mathrm{~m}^{2}$ que ocupaba dentro de tercero día, debiendo retirar todos los materiales y elementos de construcción que había introducido, con costas. Por consistencia con esa decisión, se rechazó la acción publiciana ejercida como demanda reconvencional (cons. $22^{\circ}$ ).

Después de dar por acreditado que la cosa era susceptible de ser reivindicada (cons. $7^{\circ}$ ) y que el demandado la tenía en su poder (cons. $8^{\circ}$ ), el razonamiento del tribunal se centró en establecer el dominio del demandante (cons. $9^{\circ}$ ), lo cual se dio por probado (cons. $12^{\circ}$ y $13^{\circ}$ ) de acuerdo con la prueba documental, testimonial y pericial y con la inspección personal del tribunal que constaban en el proceso (cons. $\left.10^{\circ}\right)^{2}$. El problema se producía porque los predios del demandante y el demandado eran colindantes y el segundo había comenzado a construir una vivienda en un 50\% dentro de la propiedad del primero (cons. $14^{\circ}$ ). La condena por los deterioros y frutos fue rechazada, dado que la mala fe del demandado debía ser acreditada por el actor, y no lo fue, por estar amparado por la presunción del art. 707 del $C C$, de suerte que había de ser reputado como poseedor de buena fe (cons. $16^{\circ}$ ). La prescripción alegada por el demandado fue igualmente rechazada, porque no pudo demostrar la tenencia del bien objeto del juicio, siendo solo indubitada su ocupación desde comienzos del año 2013, cuando comenzó las obras de construcción que alertaron al actor, lo cual no constituía un tiempo suficiente para considerarlo poseedor regular de ese terreno al haberse presentado la demanda el 12 de junio de ese año (cons. $21^{\circ}$ ).

Apelado ese fallo por el demandado ante la Corte de Apelaciones de Rancagua, esta confirmó la decisión por sentencia de 24 de mayo de 2017. El tribunal de alzada agregó que era imposible reconocer al apelante el derecho previsto en el art. 669 del $C C$, puesto que este está previsto a favor del dueño y se dirigía contra quien había edificado, plantado o sembrado en su propiedad y, además, no se había rendido ninguna prueba que permitiese fijar una indemnización equivalente al valor de lo construido.

\footnotetext{
${ }^{2} \mathrm{El}$ cons. $12^{\circ}$ señala que el demandado era, desde el 15 de julio de 2009, poseedor inscrito del inmueble. Sin embargo, ni de la prueba aportada por el demandando (cons. $10^{\circ}$ ) ni de aquella acompañada por el demandado (cons. $11^{\circ}$ ) consta que la escritura pública de cesión de "derechos posesorios" extendida con esa fecha hubiese sido inscrita en el Conservador de Bienes Raíces de Pichilemu, faltando así el requisito exigido por los arts. 686 y 724 del $C C$.
} 
Contra la sentencia de segunda instancia, el demandado dedujo recursos de casación en la forma y en el fondo para ante la Corte Suprema.

A través del recurso de casación en la forma se denunciaba que el fallo de segundo grado había incurrido en el vicio del art. $768, \mathrm{n} .{ }^{\circ} 5^{\circ}$ del $C P C$, en relación con el art. $170, \mathrm{n}^{\circ} 4^{\circ}$ del $C P C$, por dos razones distintas. La primera era que esa sentencia contenía consideraciones contradictorias sobre el dominio del actor, puesto que el tribunal de primera instancia lo había declarado recurriendo al régimen de saneamiento del DL 2695/1979 y la Corte de Apelaciones de Rancagua había dado cuenta de la existencia de un procedimiento de regularización "dubitado en el juicio" (cons. $2^{\circ}$ ), de suerte que con esta última afirmación se anulaba el razonamiento del juzgado de letras y su decisión quedaba desprovista de fundamentación. La segunda razón se refería a que la sentencia recurrida no se hacía cargo de todas las alegaciones y de la prueba rendida, porque en la sentencia de primer grado no existía mención al art. 669 del $C C$, como sí lo había en el fallo de alzada, pese a concluirse en este último que los antecedentes agregados al proceso no eran suficientes para llegar a un pronunciamiento al respecto. Esto, no obstante que el informe pericial, según el cual se estableció que su parte había edificado invadiendo un $50 \%$ el inmueble reclamado, daba cuenta de la existencia de obras de construcción.

El recurso de casación en el fondo denunciaba la infracción de los arts. 669, 908, 909, 912 y 914 del $C C$, al estimar que la primera de esas normas contem210 pla una acción cuyo titular es el dueño del bien raíz donde otro ha edificado, plantado o sembrado. A juicio del recurrente, el derecho de opción establecido en el citado art. 669 del $C C$ es algo distinto al ejercicio práctico de la acción, y tampoco se puede solucionar la cuestión que ella trata mediante la remisión a las normas sobre prestaciones mutuas que acompañan a la reivindicación, porque ambos se refieren a materias diversas. El mentado art. 669 del $C C$ contempla una opción a favor del dueño del inmueble, pero ella se hace efectiva al momento de acogerse la reivindicación y, por consiguiente, condenarse al demandado que ha construido, plantado o sembrado en suelo ajeno a la restitución del inmueble donde ha realizado alguna de esas acciones, siendo un mecanismo complementario al de las prestaciones mutuas. Esa complementariedad está dada por el hecho de que las prestaciones mutuas distinguen entre mejoras necesarias, útiles y voluptuarias, mientras que la regla de accesión antes mencionada supone la edificación, plantación o siembra en un terreno ajeno donde antes no había nada.

Por sentencia de 5 de junio de 2018, la Corte Suprema rechazó ambos recursos, confirmando así la decisión del juzgado de primera instancia de acceder a la reivindicación solicitada respecto del retazo de terreno en que existía coincidencia entre el dominio del demandante y la ocupación del demandado.

La casación en la forma fue rechazada porque el vicio denunciado consiste en que el fallo recurrido no contenga consideraciones de hecho y de derecho que sirvan de base a la decisión que se adoptaba, y no cuando ellas no se ajusten a la tesis que sustentaba el recurrente o resulten equivocadas, como sucedía 
en la especie (cons. $2^{\circ}$ ). En este sentido, no era cierto que la sentencia de segunda instancia hubiese reconocido como dubitado el procedimiento de saneamiento mediante el cual el demandante se procuró el título por el cual adquirió el inmueble que reclamaba, sino solo que ese dominio había sido discutido por el demandando al sostener que él era en verdad el dueño (cons. $3^{\circ}$ ). Tampoco era efectivo que el fallo de alzada no se refiriese al art. $669 \mathrm{del} C C$, puesto que los jueces sí se ocuparon de ese punto, haciéndose cargo de las alegaciones del demandado, si bien para desestimarlas (cons. $\left.3^{\circ}\right)$.

El recurso de casación en el fondo fue rechazado por no existir el yerro de derecho que el recurrente denunciaba. La Corte Suprema sostuvo que el problema jurídico del art. 669 del $C C$ consiste en dar una solución para "el destino de la edificación" cuando una persona tiene un inmueble que pertenece a otra y ha construido en él, "ofreciendo una tutela equilibrada al dueño del terreno y a quien edificó” (cons. $8^{\circ}$ ). Pero no existe duda que, con independencia del beneficiario del pago que se realice merced a esa regla, la opción es siempre del dueño, sea porque hace suyo el edificio pagando al que lo construyó, sea porque obliga a este a comprarle el terreno, de suerte que los jueces del fondo no habían vulnerado un derecho del que el demandado carecía (cons. $8^{\circ}$ ). Por otra parte, la Corte Suprema estimó que el art. 669 del $C C$ podía ser ejercido al interior del juicio reivindicatorio durante la fase de ejecución de la sentencia, dado que la opción del dueño era retener para sí el inmueble donde otro había construido (cons. $9^{\circ}$ ). De igual manera, las referencias a los arts. 908, 909, 912 y 914 del $C C$ tampoco podían resultar infringidos por la sentencia recurrida, porque ellos reciben aplicación al momento de ejecución del fallo, y no antes, puesto que están "destinados a cautelar exigencias elementales de justicia distributiva" entre el reivindicador y el poseedor vencido (cons. $9^{\circ}$ ).

\section{COMEnTARio}

Aunque ninguno de ellos acabó teniendo mayor preponderancia al momento de la decisión judicial, el caso recién reseñado admite dos niveles de lectura. El primero de ellos tiene relación con la función que cumple la inscripción como elemento configurador de la posesión sobre los bienes inmuebles y la procedencia de la acción publiciana respecto del poseedor regular. Por su parte, el segundo no se vislumbra con claridad a simple vista y atañe a aquella práctica cada vez más común de efectuar loteos irregulares por medio de vender cuotas en una comunidad (generalmente, sin señalar cuál es el porcentaje de cada una de ellas y bajo el eufemístico nombre de "derechos posesorios"), para acabar forzando la regularización de los distintitos parceleros a través del DL 2695/1979. En su origen, la Ley n. ${ }^{\circ} 21108$ estaba dirigida a evitar la proliferación de esta clase de loteos, pero el texto final solo corrige la configuración de ciertos requisitos para sanear la pequeña propiedad raíz conforme al mentado decreto ley, especialmente en lo que se refiere al aumento del plazo 
para adquirir por prescripción (art. 15) y la ampliación de la limitación para gravar y enajenar el bien una vez ganado el dominio por el poseedor que se ha sometido al procedimiento administrativo (art. 17) ${ }^{3}$.

Si bien ambos niveles son interesantes desde un punto de vista dogmático, ahora cumple ocuparse del primero de ellos, incluso cuando ninguna de las sentencias dictadas se detuvo demasiado en la función que cumple la inscripción conservatoria. Con todo, frente a una línea jurisprudencial que vulgariza el sentido técnico de la posesión en el Código Civil y las acciones que este ha dispuesto para proteger al dueño contra las distintas perturbaciones que suponen el desconocimiento de su derecho, la que ha sido tratada ya en algunos comentarios anteriores ${ }^{4}$, conviene insistir sobre la función insustituible que desempeña la inscripción a propósito de la posesión de los inmuebles (1). Ella se conecta, a su vez, con la legitimación activa para ejercer la acción publiciana (2), que el demandado ejerció sin resultados como demanda reconvencional. Pero junto a estas dos cuestiones, hay que referirse a aquella sobre la que sí versó el análisis de la Corte Suprema y que atañe a la compatibilidad que ella entiende existir respecto de las indemnizaciones que el art. 669 del $C C$ concede a quien ha construido, sembrado o plantado en suelo ajeno y las prestaciones mutuas que acompañan a la acción reivindicatoria (3).

Por cierto, es indiscutible que la decisión del Juzgado de Letras de Pichilemu, confirmada después por la Corte de Apelaciones de Rancagua y por la 212 Corte Suprema, fue correcta: correspondía acoger la demanda de reivindicación porque el demandante era dueño de parte del bien raíz donde el demandado había iniciado obras de construcción, aunque, en rigor, la causa de pedir residiese en el art. 915 del $C C$ y no en el art. 889 del $C C$. Simplemente, y como ya se está haciendo costumbre, los tribunales que resolvieron el caso estimaron que contra el poseedor material también procede la acción reivindicatoria, puesto que el requisito relevante a su respecto era la ocupación actual y física del bien reclamado. Aunque esto en verdad poco importa, porque precisamente el sentido del art. 915 del $C C$, introducido junto con todas las demás reglas que conforman la llamada "teoría de la posesión inscrita" por la Comisión Revisora, es cerrar los contornos de la protección dominical y proteger al dueño cuando un bien raíz es ocupado por un tercero que no tiene la calidad de poseedor, sin que importe que se conduzca o no como señor y dueño ${ }^{5}$.

\section{El sentido de la inscripción conservatoria}

Aunque sea majadero, hay que insistir en que las reglas sobre las que se sustenta la "teoría de la posesión inscrita" fueron introducidas recién en el así llamado Proyecto Inédito. Esto significa que no formaban parte del sistema original que

\footnotetext{
${ }^{3}$ Goldenberg (2019) analiza esta reforma.

${ }^{4}$ Véase, por ejemplo, AlCAlde (2018a) y (2019).

${ }^{5}$ AlCALDE (2019b), especialmente pp. 52-59.
} 
Andrés Bello (1781-1865) había previsto en el Proyecto de 1853 para el régimen de las cosas y que su origen proviene del primer examen al que fue sometido ese texto por parte de la comisión presidida por el presidente Manuel Montt Torres (1809-1880) y donde participaron jueces (Manuel José Cerda, Ramón Irarrázaval, Alejo Valenzuela y José Miguel Barriga), profesores universitarios (Diego Arriarán, Antonio García Reyes y Manuel Antonio Tocornal) y las tres personas que habían recibido el encargo de preparar alguno de los códigos comprendidos dentro del plan general de codificación puesto en marcha por el gobierno desde el año anterior (Andrés Bello, Antonio García Reyes y José Gabriel Ocampo) ${ }^{6}$. En esa revisión fueron añadidos los arts, 696 (art. 826 i), 724 (art. 867 a), 728 (art. 873 a), 729 (art. 874), 924 (art. 1076) y 2505 (art. 2687 b) del Código aprobado el 14 de diciembre de $1855^{7}$.

Como fuere, todas esas reglas son corolarios derivados de la regla basal del art. 686 del $C C$, que dispuso un sistema de inscripción constitutiva, vale decir, ella es la que da vida al derecho real y toda modificación inmobiliaria posterior se produce merced a un nuevo asiento registral. Esta norma provenía del Proyecto de 1853, pero tenía ahí una redacción diversa. Su art. 826 establecía un modo opcional de hacer la tradición simbólica para los bienes raíces, que era distinto del ya previsto en el artículo anterior $(825)^{8}$, el cual consistía en registrar:

"la escritura pública de enajenación en la competente oficina del Conservador de Bienes Raíces y firmando el Conservador la partida, junto con ambas partes o sus apoderados" (inc. $1^{\circ}$ ).

Practicada esta inscripción, ella impedía una nueva tradición real (art. 823) o simbólica (art. 825) en el futuro, puesto que enseguida se agregaba: "transferido de este modo el dominio, no podrá pasar a tercero sino de la misma manera" (inc. $2^{\circ}$ ).

La fuente de esta regla era el $\S 431 \mathrm{del} A B G B$ (1811), aunque Andrés Bello no lo dejó dicho 9 . Como nota al Proyecto de 1853 solo hizo presente que este medio de efectuar la tradición de los inmuebles le parecía preferible al existente en el derecho romano (Cod. 8, 53,1) y castellano (Part. 3, 30, 8), y partía del supuesto que habría en cada departamento un registro que se podía agregar al de las hipotecas implementado tras la Real Pragmática de 31 de

${ }^{6}$ Véase Alcalde (2019b), pp. 37-44.

${ }^{7}$ Aunque el inc. $3^{\circ}$ del art. 702 del $C C$ proviene del art. 835 II del Proyecto de 1853, su inc. $4^{\circ}$ solo aparece en la redacción definitiva que figura ya en el art. 834 del Proyecto Inédito. Cfr. BELLo (1954), pp. 476-477.

${ }^{8} \mathrm{El}$ art. 825 del Proyecto de 1853 era coincidente con el art. 684 del $C C$, pero se aplicaba también a los bienes raíces. Por su parte, el art. 823 se ocupaba de la tradición real de las cosas muebles e inmuebles. Respecto de los inmuebles, ella se hacía de la siguiente manera: "entrando en ellas el que las recibe, a presencia del que las entrega; manifestándose en el uno la voluntad de trasferir el dominio, i en el otro la de adquirirlo".

${ }^{9}$ Véase, por ejemplo, Bravo (2014) y Zárate (2019b), pp. 155-212. 
enero de 1768 y regulado por entonces en el Reglamento de 20 de mayo de $1848^{10}$. Concluía señalando que esta era una gran innovación del Proyecto que proponía al gobierno para su estudio, y estaba en línea con las más modernas legislaciones comparadas ${ }^{11}$.

La inspiración inmediata de este cambio radical de criterio respecto de la transferencia de propiedad sobre los inmuebles parece responder a dos razones: por una parte, las consecuencias extraídas de la adopción de un sistema de inscripción constitutiva como el previsto en el citado $§ 431$ del $A B G B^{12}$ y, por otra, la lectura del Proyecto de Código Civil español de 1851, el cual viene mencionado como fuente del art. 2505 del $C C^{13}$. Esta última regla dispone que no cabe la prescripción adquisitiva contra un título inscrito, vale decir, prohíbe la llama prescripción contra tabulas ${ }^{14}$, y es la única de las normas que conforman la "teoría de la posesión inscrita" donde Andrés Bello dejó consignada una fuente, remitiendo a las Concordancias, motivos y comentarios al Código Civil español (1852) escritas por Florencio García Goyena (1783-1855) ${ }^{15}$. De hecho, la redacción del art. 1946 II del Proyecto de Código Civil español de 1851 coincide casi de manera exacta con aquella que quedó recogida en el Proyecto Inédito y de donde pasó al Código Civil aprobado en 1855 por el Congreso Nacional ${ }^{16}$.

En un comentario anterior se ha explicado que, según Florencio García Goyena, la fuente de dicha regla era el $§ 511$ de la sección IX del título IX del 214 Código prusiano de 1794 (la PrALR) ${ }^{17}$, y constituía "un homenaje tributado al nuevo sistema hipotecario; una consecuencia rigorosa de los artículos 1826 y 1858 [del Proyecto de 1851]"18. La primera de esas normas se refería a la tradición de bienes inmuebles y era equivalente al art. $686 \mathrm{del} C C$; mientras que

${ }^{10}$ Zárate (2019a).

${ }^{11}$ BELLO (1888), pp. 186-187: "Se ha querido preparar por este medio una institución que se halla establecida hoy día con los mejores efectos en varios estados europeos”.

${ }^{12}$ Mery (1946), p. 104.

${ }^{13}$ Cfr. Amunátegui (2019), p. 633; Bello (1955), p. 1026, y Barrientos (2016), it, p. 1171. Un mayor desarrollo sobre las fuentes de sistema registral chileno puede verse en SEPÚLVEDA (2014), pp. 157-176 y ZÁRATE (2019), pp. 159-189, 202-210 y 275-278.

${ }^{14}$ Cavanillas (2018), pp. 336-342.

${ }^{15} \mathrm{Al}$ margen del art. $2687 \mathrm{~b}$ del Proyecto Inédito, Andrés Bello hizo la siguiente anotación: “Goy., Concordancia, 1946”. En su biblioteca personal había un ejemplar de esa obra, según refiere Veleman (1995), p. 177.

${ }^{16}$ Curiosamente, LIRA (1956), p. 85, señala: "falta por entero en García Goyena la institución de la posesión inscrita"; mientras que LASSO (1970), p. 294, califica el libro II del Código Civil chileno como de factura "más próximo al Code".

${ }^{17}$ PrALR I 9 § 511: "Los derechos sobre cosas inmuebles que se encuentran inscritos en el Registro de Hipotecas no pueden extinguirse por la mera falta de uso, ni puede adquirirse un derecho contrario por medio de la prescripción por posesión" "Rechte auf unbewegliche Sachen, die im Hypothekenbuche eingetragen sind, können weder durch den bloßen Nichtgebrauch erlöschen, noch kann ein denenselben entgegenstehendes Recht mittelst der Verjährung durch Besitz erworben werden”). El autor agradece al Dr. Andrés Schlack Muñoz por la traducción desde el alemán.

${ }^{18}$ García Goyena (1974), p. 1002. 
la segunda disponía que ninguno de los títulos que se debía inscribir producía efectos respecto de terceros hasta que se hubiese practicado la inscripción respectiva, con un efecto similar al que subyace en el art. $696 \mathrm{del} C C^{19}$. De hecho, la imposibilidad de prescribir un bien raíz en tanto no se haya cancelado la inscripción existente respecto de una persona distinta al prescribiente también está recogida en el $\S 902$ del $B G B$, puesto que comporta una consecuencia necesaria del carácter constitutivo de la inscripción como forma de tradición.

El problema estriba en que la lectura del sistema diseñado por el Código Civil para el régimen de las cosas ha resultado distorsionada por la introducción de la "teoría de la posesión inscrita" desde comienzos del siglo xx, aun cuando se haya intentado ir más atrás en sus orígenes ${ }^{20}$. Con todo, el antecedente remoto de esta teoría se encuentra en la justificación que hace el Mensaje del Código Civil de las novedades introducidas acerca del dominio, uso y goce de los bienes, donde la posesión viene descargada de la nomenclatura embarazosa y ambigua que por entonces existía ${ }^{21}$ y que todavía estaba presente en el Proyecto de $1853^{22}$. Para lo que ahora interesa, ahí se dice que en algunos ordenamientos extranjeros la inscripción es una garantía de la propiedad, y no solo de la posesión, pero que el Código Civil chileno no quiso (en apariencia) ir tan lejos ${ }^{23}$.

${ }^{19}$ La relación entre inscripción y tradición ha suscitado diversas opiniones en la doctrina española con posterioridad la Ley Hipotecaria (la primera de ellas de 8 de febrero de 1861; la actual data del 8 de febrero de 1946) y el Código Civil (1889). Se admite como principio que la inscripción no ha sustituido a la tradición. La razón es que en el Registro de la Propiedad se inscriben los cambios jurídicos operados de acuerdo con el derecho común (arts. 605 del Código Civil y 1 de la Ley Hipotecaria), por lo que es necesario que haya habido tradición para que exista transferencia de dominio (art. 609 del Código Civil). El art. 1462 del Código Civil señala que la cosa vendida se entiende entregada cuando se pone en poder y posesión del comprador; pero agrega que, cuando la venta se hace mediante escritura pública, el otorgamiento de esta equivale a la entrega, si de la misma escritura no resultare o se dedujere claramente lo contrario. Esta escritura es requerida, asimismo, por la Ley Hipotecaria para practicar la inscripción (arts. 2 y 3). De esto se sigue que en la mayoría de los casos no hay problema, pues existe coincidencia entre los efectos de la tradición y la subsecuente inscripción: si el transferente no es dueño, la escritura pública no puede tener eficacia dominical. La cuestión se suscita respecto de terceros, puesto que el art. 606 del Código Civil señala que los títulos de dominio, o de otros derechos reales sobre bienes inmuebles, que no están debidamente inscritos o anotados en el Registro de la Propiedad, no perjudican a terceros. Así, pues, respecto del tercero protegido por el art. 34 de la Ley Hipotecaria y que procede por analogía en la forma establecida en el art. 36 de la misma ley, la fe pública registral subsana este presupuesto de adquisición, de manera que la inscripción sí suple la tradición. Véase Rodríguez-Rosado (2012) y (2014).

${ }^{20}$ BARAHONA (2016) revisa el estado de la cuestión en la doctrina y la jurisprudencia anterior al trabajo señero de Humberto Trucco.

${ }^{21}$ Mensaje del Código Civil, §§ 18 y 21.

${ }^{22}$ BeLlo (1888), pp. 187-188: "Las dificultades en materia de posesión, que son gravísimas, provienen principalmente de la inexactitud del lenguaje. Es preciso distinguir las varias especies de posesión. $1^{\text {a }}$. Posesión unida al dominio. $2^{\text {a }}$. Posesión del que no es dueño acompañada de justo título y buena fe: posesión civil. $3^{\mathrm{a}}$. Posesión del que no es dueño, no acompañada de justo título o de buena fe: posesión natural. [...] No se ha adoptado en este Proyecto la nomenclatura de las Partidas en que a la posesión se llama tenencia, y se definen de diferente modo la posesión civil y la posesión natural”. Véase, asimismo, BARRIENTOS (2016), pp. 909-915.

${ }^{23}$ Mensaje del Código Civil, § 21. 
La pregunta que se sigue de esta afirmación se refiere al alcance del cambio de paradigma que introdujo la Comisión Revisora respecto del régimen de las cosas, que alteró de manera radical la disciplina que existía hasta entonces.

Una primera respuesta puede ser que el sistema de inscripción constitutiva no fue cabalmente comprendido por los comisionados, lo que explica la existencia de algunas normas asimétricas cuyo intento de racionalización debió ser emprendido más tarde por la doctrina con resultados no satisfactorios $^{24}$. Ejemplo de ello son las discusiones que se han suscitado en torno a la enigmática acción del art. 915 del $C C$, para conciliar los arts. 924 y 925 del $C C$ a propósito de la prueba de la posesión o para precisar el alcance de la prescripción adquisitiva extraordinaria del art. $2510 \mathrm{del} C C$.

Otra alternativa consiste en estimar que el problema no reside en los textos del CódigoCivil, sino en la lectura que se ha hecho de ellos. Esta parece una respuesta más acorde con el sentido de la "revolución científica" que se introdujo al adoptar un modelo de inscripción constitutiva obligatoria. No hay que olvidar que el origen directo de la formulación de la "teoría de la posesión inscrita" se encuentra en las memorias de grado escritas a comienzos del siglo $\mathrm{xx}$ por tres estudiantes de derecho de la Universidad de Chile que compartían el mismo nombre: Humberto Trucco Franzani (1882-1951), Humberto Mewes Bruna (1889-1972) y Humberto Álvarez González (1905-1986) ${ }^{25}$. El primero, quien después se desempeñó como presidente de la Corte Suprema durante dos periodos (1934-1937 y 1944-1950) y profesor de Derecho Procesal en la universidad donde cursó sus estudios, es el autor que más influencia tuvo en la construcción de esta teoría. En su trabajo reaccionó contra una tendencia jurisprudencial, que estimaba conducía hacia un debilitamiento del régimen de posesión inscrita, y lo hizo postulando que la inscripción es una ficción legal y que en ella confluyen figurativamente los dos elementos de la posesión (tenencia y ánimo de señor y dueño), de suerte que solo mediante esa inscripción puede existir verdadera posesión sobre un inmueble ${ }^{26}$. Humberto Mewes matizaba esta conclusión, señalando que la inscripción es casi siempre prueba de posesión, pero existían casos en que eso no ocurría y, por ende, era necesario analizar las causas próximas y remotas de la adquisición del dominio por cada uno de los poseedores del inmueble, vale decir, realizar lo que en la práctica forense se conoce como un "estudio de títulos"27. En fin, Humberto Álvarez defendía que la inscripción era la que concedía la posesión regular sobre el inmueble, pero eso no impedía que sin inscripción no pudiese adquirirse una posesión irregular ${ }^{28}$. Con eso se abría paso a un nuevo elemento de distorsión del sistema y que se relaciona con el campo de aplicación de la prescripción

\footnotetext{
${ }^{24}$ Zárate (2019b), p. 268.

${ }^{25}$ Larroucau (2015), pp. 130-133.

${ }^{26}$ Trucco (1910).

${ }^{27}$ Mewes (1913).

${ }^{28}$ Álvarez (1926).
} 
adquisitiva extraordinaria, por el conflicto normativo que se produce entre los arts. 2505 y 2510 del $C C^{29}$, si bien la jurisprudencia se ha inclinado por dar primacía a la primera de esas reglas y salvaguardar así el principio de legitimación registral ${ }^{30}$.

El trabajo de Humberto Trucco fue publicado en la Revista de Derecho y Jurisprudencia, donde también apareció en 1934 el trabajo de Leopoldo Urrutia Anguita (1849-1936), por entonces ya jubilado tanto de la Corte Suprema como de su cátedra de Derecho Civil en la Universidad de Chile, sobre la restringida función que desempeña la inscripción, reservada a ser una garantía de la posesión contra actos físicos de apoderamiento y siempre que ella sea real, y no puramente de papel ${ }^{31}$. Con la lectura de este muy influyente trabajo se comprueba, además, cómo la doctrina de la posesión inscrita se había consolidado después del trabajo de Humberto Trucco gracias al aporte de la doctrina y la jurisprudencia ${ }^{32}$. A su vez, con ambos quedaron planteadas las doctrinas de la inscripción-ficción y de la inscripción-garantía sobre la que ha basculado la discusión posterior en torno a la materia ${ }^{33}$.

Todos estos trabajos acabaron por desplazar el centro de gravedad desde la función constitutiva que tiene la inscripción respecto de la titularidad dominical hacia la prueba de la posesión, con la consiguiente distorsión que esto significa para la comprensión de aquel grado de tenencia. Porque, si bien es cierto que el sistema registral instituye un régimen posesorio de carácter técnico, que sustituye al concepto clásico de posesión física que recoge el art. 700 del $C C$, no se puede soslayar que esa consecuencia deriva de la función de modo de adquirir el dominio que el mismo código atribuye a la inscripción como forma de practicar la tradición (art. 686 del $C C$ ). En otras palabras, y como es propio de la mentalidad codificadora que ordena las relaciones jurídicas a partir de un esquema formal de derechos subjetivos, la posesión queda conformada bajo las mismas pautas de la propiedad, como una apariencia de esta, desplazando su componte histórico principal: la facticidad. Por eso, el mismo art. 700 del $C C$ señala que la posesión puede ser dominical ("sea que el dueño [...] tenga la cosa") o no dominical ("sea que [...] el que se da por tal tenga la cosa"), y ejercerse por el propio poseedor ("sea que el dueño o el que se da por tal tenga la cosa por sí mismo") o por otra persona en su nombre ("sea que el dueño o el que se da por tal tenga la cosa [...] por otra persona que la tenga en lugar y nombre de él”).

${ }^{29}$ De esto se ha tratado en AlCALDE (2019c).

${ }^{30}$ Véase, por ejemplo, SSCS de 23 de marzo de 2016 (CL/JUR/1830/2016), 28 de abril de 2016 (CL/JUR/3060/2016), 8 de junio de 2016 (CL/JUR/3789/2016), 28 de agosto de 2017 (CL/JUR/5633/2017), 31 de enero de 2018 (CL/JUR/521/2018), 12 de julio de 2018 (CL/ JUR/3768/2018), y 29 de noviembre de 2018 (CL/JUR/6642/2018), así como la jurisprudencia más antigua referida en Figueroa (1996), pp. 224-227.

${ }^{31}$ Urrutia (1934).

${ }^{32}$ Detrás está también el cambio de paradigma en la enseñanza del derecho y la difusión de las nuevas tendencias a través de la Revista de Derecho y Jurisprudencia, creada en 1903. Véase Amunátegui (2016), pp. 22-23.

${ }^{33}$ Véase, por ejemplo, PeÑailillo (2019), pp. 1016-1021. 
De esto se sigue que la dimensión material de la posesión solamente desempeña una función relevante respecto de las cosas muebles (de ahí el aforismo "en fait de meuble possession vaut titre" ${ }^{34}$ ) y como elemento basal para distinguir en abstracto (como categorías normativas) entre los grados de detentación que admite el derecho (posesión y mera tenencia) ${ }^{35}$. Por lo demás, el Mensaje del Código Civil hace patente esta ruptura con la tradición jurídica anterior, expresando las razones y el funcionamiento del nuevo sistema previsto para las titularidades ${ }^{36}$, de suerte que su texto resulta un elemento indispensable para conocer la intención del legislador en torno a esta materia (art. 19 II del CC). Lamentablemente, no ha sido aprovechado lo suficiente ${ }^{37}$.

En dicho Mensaje se define la posesión de una manera que suele pasar desapercibida, quedando su estudio reducido al concepto del mentado art. 700 del $C C$, vale decir, como una tenencia calificada por el ánimo de señor y dueño que muestra el poseedor. El § 24 dice que ella puede ser siempre reconducida a un "carácter genérico que consiste en la investidura de un derecho real" 38 , sin importar que esté respaldada por "la realidad o la apariencia de dominio". Esta caracterización de la posesión es muy significativa, porque remite a la idea que de ella se tenía en el derecho germánico y que se conoce con el nombre de gewere. Este término denota la forma de un derecho real, puesto con ella se designa el señorío fáctico sobre una cosa, que resulta oponible frente a todos por su carácter ostensible ${ }^{39}$.

218 Esta sustitución del concepto de posesión no es propia del derecho chileno, sino que constituye una tendencia asentada en el derecho comparado. Jerónimo González Martínez (1875-1949), reconocido como el primero de los cultivadores del derecho hipotecario en España, lo explicaba de esta forma hace ya casi un siglo al referirse a las dos funciones que cumple el principio de publicidad registral:

"Como principio legitimador, derivado directamente de gewere o investidura germánica, reemplaza a la misma propiedad con su forma jurídica, y la protege en sus apariencias, mediante una presunción juris tantum suficiente para la vida práctica. Para que ésta se desenvuelva normalmente mientras no haya terceros interesados, basta suponer que la inscripción corresponde

${ }^{34}$ Peñallillo (2019), pp. 1422-1442.

${ }^{35}$ El Mensaje del Código Civil, § 24 señala: "las palabras posesión y tenencia contrastan siempre en él [el Proyecto de Código Civil], la posesión es a nombre propio, la tenencia a nombre ajeno». Véase la observación hecha por la Corte de Apelaciones de La Serena respecto del art. 714 del $C C$ (art. 854 del Proyecto de 1853), que recoge Mery (1946), p. 106.

${ }^{36}$ Hanisch (1996), p. 208.

${ }^{37}$ Por ejemplo, el trabajo de Hugo Hanisch Espíndola (1915-1992) citado en la nota anterior se limita a parafrasear el Mensaje, sin aportar mayores luces sobre el sentido de cada una de las frases que ahí se dedica al régimen de las cosas.

${ }^{38}$ La expresión coincide con la definición de gewere que da Vinogradoff (1918), p. xxviii: "the matter of fact expression of real rights".

${ }^{39}$ Planitz (1957), pp. 99 y 154. 
a la realidad jurídica y acredita prima facie que el derecho inscrito existe y que el cancelado se ha extinguido.

$[\ldots]$

La técnica moderna concede a la inscripción respecto de los inmuebles, las mismas funciones legitimadoras que a la posesión corresponden en el orden de los inmuebles" ${ }^{40}$.

La decisión adoptada en la Comisión Revisora consistió en convertir la posesión de los inmuebles en un concepto donde la tenencia material no importa mientras subsista la solemnidad de la inscripción conservatoria, porque es ella la que permite identificar al sujeto bajo cuya esfera de control se encuentran esos bienes. Sin embargo, el elemento caracterizador de este grado de detentación no estriba tanto en la disponibilidad física de la cosa, precisamente porque ella resulta irrelevante para su configuración, sino en el control económico que entrega sobre ella, que permite que pueda ser ejercido por intermedio de otros (arts. 700, 714 y 725 del $C C$ ) y que la posesión no se pierda por la ausencia de su titular (art. $727 \mathrm{del} C C$ ) $^{41}$. Por eso es tan importante el sentido del art. 696 del $C C$ cuando dice que la inscripción conservatoria es la que concede la posesión efectiva sobre un determinado bien raíz, puesto que ella es la que permite ejercer el máximo acto dominical: la disposición. La suerte de esa tradición (art. 686 del $C G$ ) depende de la calidad dominical o no dominical del poseedor que transfiere la cosa (art. 682 del CC).

Esto significa que el sistema posesorio del Código Civil fue mucho más allá que los modelos comparados, porque unificó en un solo régimen tres situaciones distintas: inscripción, posesión y $\operatorname{propiedad~}^{42}$. Jerónimo González lo explica así:

"Si la posesión consiste principalmente en un señorío de hecho sobre las cosas, en un sometimiento efectivo a la voluntad humana, la llamada posesión registral o titular, basada sobre la inscripción de una finca o derecho real en el Registro a favor de una persona determinada, no es verdadera posesión. La titularidad emanante del asiento no implica una potestad inmediata sobre la cosa ni ejercicio del derecho. De aquí que pueda aparecer como poseedor jurídico una persona no inscrita.

Un imperfecto paralelismo entre la gewere, o investidura germánica, y la posesión romana, puede llevar a la confusión de ambos conceptos; pero en el orden inmobiliario la primera se caracteriza por la fuerza legitimadora y valor transmisivo, así como la segunda por ser relación de hecho, a la que el derecho concede enérgica e inmediata protección" ${ }^{43}$.

\footnotetext{
${ }^{40}$ GonZÁlez (2009), pp. 122-123.

${ }^{41}$ D'Ors (1995), p. 25.

${ }^{42}$ Mensaje del Código Civil, § 22.

${ }^{43}$ González (2009), pp. 132-133.
} 
La situación es distinta para el derecho chileno. En el Código Civil sí existe perfecta equivalencia entre inscripción conservatoria y posesión, siendo esto una consecuencia de que ella quedó establecida como el único modo de transferir el dominio de los inmuebles (art. 686 del $C C$ ). El objetivo era claro, pero de largo plazo:

"Pero como no sólo los actos entre vivos sino las transmisiones hereditarias están sujetas respecto a los bienes raíces a la solemnidad de esta inscripción, todos los referidos bienes, a no ser los pertenecientes a personas jurídicas, al cabo de cierto número de años se hallarán inscritos y al abrigo de todo ataque" ${ }^{44}$.

Bajo el solo régimen del Código, entonces, no puede existir poseedor de un inmueble que no tenga a su favor una inscripción conservatoria. De esto se sigue que fue correcto el razonamiento del Juzgado de Letras de Pichilemu cuando concluyó que el dominio del demandante se da por establecido merced a la inscripción conservatoria (cons. $13^{\circ}$ ), aun cuando resulta llamativo que se califique de poseedor inscrito al demandado por el hecho de tener a su favor una escritura pública de cesión de "derechos posesorios" (cons. $\left.12^{\circ}, \mathrm{c}\right)$. El régimen del DL 2695/1979 desafía al Código Civil, pero solo en la fase inicial del procedimiento de saneamiento. Lo hace al configurar con una tipicidad propia 220 la categoría de poseedor material, que supone la tenencia física de la cosa sin reconocer dominio ajeno (arts. $2^{\circ}$ y $4^{\circ}$ ). Pero el objetivo de la regularización es que el poseedor material se convierta en poseedor inscrito, sirviéndose de la resolución administrativa como título y pudiendo ganar así la cosa por prescripción adquisitiva (art. 15). Esto significa que, a fin de cuentas, el DL 2695/1979 acaba convergiendo con el régimen del Código Civil.

De este modo, aunque la función de la inscripción se asumió como parte de la acreditación de la legitimación del demandante, la tendencia a conceder la reivindicación contra los poseedores materiales acaba teniendo una ventaja, pues permite unificar la protección dominical del Código Civil con la del régimen especial del DL 2695/1979. Todo estriba en admitir que se trata de una acción general (aquella destinada a proteger el dominio de perturbaciones jurídicas) que admite diversas posibilidades de ejercicio.

\section{La acción publiciana}

No es ahora el momento de hacer una reconstrucción histórica en torno a la acción publiciana, que se concede al poseedor que está en vías de ganar la cosa por prescripción para recuperarla de quien la tenga con peor derecho $(\text { art. } 894 \mathrm{del} C C)^{45}$. Basta con decir que el ejercicio de la rei vindicatio no estaba

${ }^{44}$ Mensaje del Código Civil, § 21.

${ }^{45}$ Véase, por ejemplo, el esfuerzo monográfico de Cuesta (1984). 
previsto en el derecho romano para el poseedor que no era dueño y dejó de poseer, quien debía esperar el cumplimiento de los plazos de usucapión para ser considerado poseedor civil y poder servirse así de la acción reivindicatoria. En el siglo I a. C. se introdujo una acción especial destinada a subsanar ese estado de indefensión, la que fue conocida como acción publiciana (actio Publiciana), quizá porque provino de un pretor del año 67 llamado Quinto Publicio. Dicha acción se concedía

i) al adquirente de una res mancipi respecto de la cual se había omitido un modo solemne de adquirir (mancipatio o in iure cessio) y

ii) al que recibió por una tradición no dominical cualquier cosa identificable, sin importar si hubo un modo solemne de adquirir tratándose de una res manicipi ${ }^{46}$.

En otras palabras, era una acción que podía ser ejercida por quien adquirió la posesión mediante tradición (traditio) y luego la perdió sin voluntad de su parte, basada en la ficción de la usucapión cumplida (Gai. 4, 36). Ella quedó recogida después en Dig. 6, 2 (De Publiciana in rem actione).

En el derecho común, la acción publiciana siguió siendo utilizada ${ }^{47}$. De hecho, la práctica forense germana la prefería a la reivindicatoria por ser más fácil de demostrar sus requisitos. Su pervivencia a partir de la codificación fue muy distinta por las decisiones adoptadas respecto de la transferencia de la propiedad ${ }^{48}$. En la mayoría de los países, esta acción fue suprimida o muy discutida su pervivencia ${ }^{49}$. Por ejemplo, el derecho alemán y suizo no la conocen, y lo mismo se concluye para el derecho francés e italiano. Sí existió en la zona del derecho común y predomina la idea de que también se la aceptó en Austria, donde acabó siendo recogida como una acción restitutoria de mejor posesión ( $\$ 372 \operatorname{del} A B G B)$.

Tal era, en apretada síntesis, la evolución que había experimentado la acción publiciana y con la que se encontró Andrés Bello al redactar el Código Civil chileno. A diferencia de lo que ocurría en la mayoría de los países que tuvo en cuenta, optó por conservar esta acción en el art. 894 del $C C$, sirviéndose de fuentes romanas y de Robert Pothier (1699-1772) ${ }^{50}$. Ella quedó configurada como una acción equivalente a la reivindicatoria ("se concede la misma acción [...]") y dispuesta en beneficio del "que ha perdido la posesión regular de la cosa, y se hallaba en caso de poder ganarla por prescripción", para que pueda recuperarla de manos de cualquier otro poseedor de peor derecho. La razón de este alcance proviene de que "sólo la posesión regular pone al poseedor en el camino de la prescripción adquisitiva" ${ }^{\text {"51 }} \mathrm{y}$, por consiguiente, de convertirlo en dueño de la cosa.

${ }^{46}$ Guzmán (1996), p. 507.

${ }^{47}$ Coing (1996), I, p. 379.

${ }^{48}$ SCHiele (2019), pp. 97 y 100.

${ }^{49}$ Coing (1996), II, p. 483 y Sciumè (1989), pp. 46-47.

${ }^{50}$ Cfr. Amunátegui (2019), p. 248 y Barrientos (2016), it, pp. 1035-1037.

${ }^{51}$ Mensaje del Código Civil, $\$ 24$. 
Una acción fundada en el mejor derecho para poseer se explica por las decisiones tomadas respecto del régimen de las cosas a partir del Proyecto Inédito. Desde entonces, el núcleo de la tradición es esencialmente dominical o relativo a la titularidad sobre otros derechos reales, eliminando la distinción que hacía el Proyecto de 1853 entre la tradición del dominio (art. 806) y aquella que atañía a la posesión $\left(\right.$ art. 841) ${ }^{52}$. Esta última fue reemplaza por una regla que, sin incidir sobre la tradición en sí (ella sigue siendo válida porque no se afectan sus elementos estructurales: consentimiento, capacidad, título, solemnidades), supedita sus efectos al hecho de ser el transferente dueño de la cosa o un simple poseedor de la misma (art. 682 del $C C$ ). Esto quiere decir que el adquirente puede creer que es dueño de la cosa, porque existía un título traslaticio de dominio y hubo tradición, sin que de verdad lo sea, puesto que el transferente no podía transferirle una titularidad de la que carecía. Para recuperar la cosa cuando la ha perdido y otro la pretende con ánimo de señor y dueño, al poseedor regular le basta con probar su mejor derecho sobre ella, dado que la tradición lo ha puesto en la senda de convertirse en dueño por prescripción adquisitiva.

Así, pues, la decisión del Juzgado de Letras de Pichilemu fue correcta al rechazar la acción publiciana ejercida como demanda reconvencional por el demandado, pese a que el único argumento mencionado era que, con carácter previo se había acogido la demanda principal y ambas resultaban contradictorias entre sí (cons. $22^{\circ}$ ). En rigor, debería haber habido algún pronunciamiento 222 respecto de un hecho todavía más relevante, como era la ausencia de la calidad de poseedor regular del demandado, lo que impedía que tuviese legitimación para ocurrir de acuerdo con el art. $894 \mathrm{del} C C$. La razón residía en lo ya expuesto: no hay posesión mientras no medie una inscripción conservatoria a favor del poseedor ${ }^{53}$, y ella no existía respecto del demandado.

\section{La regla del art. 669 del $\mathrm{CC}$ y las prestaciones mutuas}

Queda tratar del último aspecto jurídico relevante en el caso aquí comentado. La discusión en las Cortes acabó versando sobre el art. 669 del $C C$, que el demandado estimó que no había sido aplicado por los jueces del fondo y, por consiguiente, esa decisión le privaba de la indemnización que esa regla establece por el valor de lo que se ha edificado, sembrado o plantado en suelo ajeno. La Corte Suprema consideró que dicha norma contempla un derecho de opción a favor del dueño (cons. $8^{\circ}$ ) y que, según cual sea la decisión por la que este se decante, la indemnización a favor del tercero puede ser discutida durante la fase de ejecución de la sentencia que accedió a la reivindicación (cons. $9^{\circ}$ ).

La primera afirmación es correcta y se desprende de la sola lectura de esta norma aplicable a la accesión industrial. Ella parte de un supuesto basal, como es el caso en que se ha edificado, plantado o sembrado en un inmueble

\footnotetext{
${ }^{52}$ Schiele (2019), pp. 91-97.

${ }^{53}$ Véase el desarrollo de esta idea en Alcalde (2019c).
} 
que pertenece a otro. La diferencia específica consiste en si esa edificación, plantación o siembra se ha hecho sin el conocimiento (inc. $1^{\circ}$ ) o a ciencia y paciencia (inc. $2^{\circ}$ ) del dueño del terreno, pero ella solo incide en que este último tenga un derecho de opción (como ocurre en la primera hipótesis) o carezca de ella (como sucede en la segunda hipótesis), sin que ninguno de esos casos suponga una completa desprotección patrimonial. Por cierto, en ambos casos es necesario que no exista un contrato que regule las relaciones entre las partes, porque entonces es esa disciplina la que absorbe la decisión sobre la suerte de la edificación, plantación o siembra, como sucede en el usufructo (art. 797 del CC) o en el arrendamiento (art. $1935 \mathrm{del} C C)^{54}$. En otras palabras, el art. 669 del $C C$ se refiere al supuesto en que la edificación, plantación o siembra se hace sin que medie un convenio regulador entre el dueño y el tercero, siendo indiferente que el primero ignore la situación o que, conociéndola, la tolere.

Cuando la accesión de cosas muebles a un bien raíz se ha hecho sin el conocimiento del dueño, este tiene derecho a

i) hacer suyo el edificio, la plantación o la sementera mediante el pago de las indemnizaciones previstas para los poseedores de buena o mala fe en la disciplina de la reivindicación o, bien, a

ii) obligar al que edificó o plantó a pagarle el justo precio del terreno con el interés corriente por todo el tiempo que lo haya tenido en su poder, y al que sembró a enterarle la renta y la indemnización de perjuicios (art. 669 I del CC).

Por el contrario, cuando se ha edificado, plantado o sembrado a ciencia y paciencia del dueño del predio, este solo puede recuperar la cosa pagando el valor de aquello que se ha agregado a él (art. 669 II del $C C$ ).

En el caso que sirve de base a este comentario, el supuesto era más cercano al primero de los mencionados, aunque no exactamente coincidente con él: el demandado había construido una vivienda ocupando una superficie equivalente al 50\% del predio de su vecino, y lo había hecho sin su conocimiento. En apariencia, esto significaba que el demandante gozaba del derecho alternativo previsto en el mentado art. $669 \mathrm{I}$ del $C C$. La pregunta a la que eso aboca tiene relación con el modo de ejercicio de dicho derecho, y eso conduce a la segunda parte del razonamiento de la Corte Suprema, según el cual el dueño debe recobrar lo que le corresponde durante la fase de ejecución del fallo.

En este último punto reside el problema, puesto que resulta difícil aceptar la compatibilidad entre las indemnizaciones del art. 669 del $C C$ y las prestaciones mutuas que acompañan la reivindicación, puesto que ambas se ordenan hacia el mismo fin: se trata de reglas destinadas a corregir el desequilibrio patrimonial causado por un supuesto de enriquecimiento injustificado ${ }^{55}$. Si bien no cabe

${ }^{54}$ Peñailillo (2019), pp. 721-722 y Ramos (1985), p. 141.

${ }^{55}$ PINo (2019), pp. 382-386, considera que se trata de situaciones diversas: en el art. 669 del $C C$ hay un supuesto de enriquecimiento injustificado por desplazamiento patrimonial, mientras que en las reglas de los arts. 906 y 907 del $C C$ existe un enriquecimiento por ganancias ilícitas. 
duda de que la restitución del inmueble donde otro ha construido, sembrado o plantado se debe lograr mediante el ejercicio de la acción real que corresponda (sea la reivindicatoria, aquella del art. $915 \mathrm{del} C C$, la publiciana o la de precario), la cuestión estriba en determinar cómo se tramita la discusión sobre el pago de los rubros accesorios ${ }^{56}$. Como ellos corresponden al demandado, será este el que deberá señalar que la construcción ha sido hecha por su cuenta y que la sentencia debe reconocer esa condición y ordenar el pago de lo que valga. Esto podrá hacerlo como excepción al contestar la demanda o, bien, como una pretensión independiente ejercida a través de una demanda reconvencional. Si no lo hizo en esa oportunidad, siempre tendrá la posibilidad de discutir las prestaciones a las que esté obligado el vencedor por vía incidental durante la fase de ejecución del fallo (art. 239 del CPC). El demandado hizo esas alegaciones durante el periodo de discusión y el tribunal de primera instancia reconoció su carácter de poseedor de buena fe para los efectos de las prestaciones mutuas (cons. $16^{\circ}$ ). Tenía derecho, por ende, a que le fuesen abonadas las obras en cuanto hubiesen aumentado el valor venal del predio (art. 909 del $C$ C).

Sin embargo, el caso deja una cuestión latente relativa a la pertinencia de la acción ejercida por el demandante. Ha quedado dicho que la reivindicación fue correctamente acogida, aun cuando el fundamento fuese el art. 915 del $C C$, puesto que el actor era dueño del bien raíz que reclamaba y tenía derecho a ser restablecido en el pleno aprovechamiento material sobre este. Siendo esto 224 así, no deja de ser verdad que existe una acción que resultaba más apropiada al caso: la denuncia de obra nueva (arts. 930 y $931 \mathrm{del} C C$ ), que, incluso, alcanza al que está ejecutando la construcción para que la detenga (art. 566 del CPC).

En fin, la Corte Suprema desaprovechó la oportunidad para pronunciarse sobre el criterio de solución aplicable a la "accesión inversa", que se da cuando ciertas construcciones han sido levantadas en parte en terreno ajeno y en parte en terreno propio y es el titular de la edificación quien se hace dueño del predio que la soporta ${ }^{57}$. En rigor, tal era la situación que se discutió en el caso, puesto que el demandado había construido una vivienda invadiendo un $50 \%$ de la superficie del predio del actor. Pero la Corte no se decantó por la solución que prima en derecho comparado y dio aplicación al art. 669 del $C C$ por analogía (aunque sin decirlo), reenviado la discusión a la fase de ejecución de la sentencia que acogió la reivindicación.

\section{CONCLUSIONES}

El caso comentado tuvo una decisión que se mantuvo sin alteraciones durante toda la tramitación de la causa. La acción reivindicatoria ejercida por el actor fue acogida, sin hacer lugar a las alegaciones del demandado sobre la proce-

\footnotetext{
${ }^{56}$ Ramos (1985), p. 146.

${ }^{57}$ Peñallillo (2019), pp. 725 y 729.
} 
dencia del art. 669 del $C C$, que concede el derecho a ser indemnizado a quien construido, plantado o sembrado en un terreno ajeno. Ninguno de los tribunales que intervino en el asunto hizo un mayor desarrollo de la calidad jurídica de las partes, limitándose a dar por establecido que, merced a la inscripción conservatoria que existía a su nombre por el tiempo requerido, el demandante era dueño del inmueble que había regularizado conforme al procedimiento del DL 2695/1979. Esto demuestra cuán admitido está en el derecho chileno el principio de legitimación registral, según el cual se asume la veracidad de lo inscrito en el registro conservatorio mientras no se demuestre su inexactitud $\mathrm{y}$, por consiguiente, se presume que el derecho inscrito existe y pertenece al titular de la inscripción.

En los últimos años, la jurisprudencia ha experimentado un vuelco importante en la concepción de la acción reivindicatoria, decantándose por una visión más funcional destinada a proteger al dueño frente a las perturbaciones de su derecho. Si bien esta tendencia vulgarizadora es criticable, porque desdibuja las categorías dogmáticas del Código Civil, tiene a su favor un punto destacable, ya que permite unificar el régimen posesorio, evitando que quede fuera el poseedor material (categoría reconocida por el citado DL 2695/1979) como posible sujeto pasivo de la reivindicación. Para lograr ese cometido, basta con entender que la acción de dominio es una categoría amplia que comprende distintos supuestos, desde el más específico entre el dueño no poseedor y el poseedor no dueño (arts. 889, 893 y 895 del $C C$ ), hasta aquellos más amplios en que la disposición subjetiva del ocupante del bien no importa (art. 915 del $C C$ ) y tampoco la prueba del dominio del demandante (art. 894 del CC). Con todo, en el caso comentado esta cuestión no fue objeto de un mayor análisis. Quizá el único punto preocupante sea la condición de poseedor inscrito que la sentencia de primera instancia reconoció al demandado, cuando solo gozaba de una escritura pública de cesión de "derechos posesorios".

Donde sí se produjo discusión, especialmente en la Corte de Apelaciones de Rancagua y en la Corte Suprema, fue a propósito del art. 669 del $C C$ y el derecho que ahí se contempla para que el ha edificado, plantado o sembrado en suelo ajeno sea indemnizado por el dueño. Esta regla establece una opción para este último, a fin de que escoja entre quedarse con la cosa y lo que a ella se ha añadido u obligue al tercero a comprarle el inmueble. Pese a que esto es cierto, hay un aspecto que pasó desapercibido y que comporta el supuesto de hecho de una figura distinta. Se trata de la llamada "accesión inversa", que se produce cuando la construcción se produce en parte en el terreno de otro y en parte en el propio. Eso fue lo que sucedió en este caso. Para la Corte Suprema, la solución a este problema parece ser la misma que en la accesión industrial propiamente tal, vale decir, dar aplicación al mentado art. 669 del $C C$. Sin embargo, esta norma no resulta compatible con las prestaciones mutuas que acompañan la reivindicación, puesto que ambas se valoran de igual forma. Lo razonable es entender que, ejercida la acción reivindicatoria, los rubros a los que tiene derecho el poseedor vencido por aquellas obras que ha efectuado 
en el inmueble se pagan de acuerdo con las reglas de las prestaciones mutuas. Por el contrario, el art. 669 del $C C$ se aplicará cuando no se haya ejercido esa acción y sea preciso determinar a cuánto asciende la compensación que puede reclamar el tercero.

\section{BibliografíA}

Agüero San Juan, Claudio (2017). "La expresión 'nulidad de derecho público' en el derecho chileno", Eunomía. Revista en Cultura de la Legalidad, n. ${ }^{\circ}$ 12. Madrid.

AlCalde Silva, Jaime (2019a). "La acción del artículo 915 CC es equivalente a la acción reivindicatoria propiamente tal, siendo competencia del tribunal efectuar la calificación sobre la forma en que el demandado ocupa el bien que se reclama. No resulta admisible la prescripción adquisitiva extraordinaria contra título inscrito. La acción reivindicatoria tiene por fin que la titularidad del dueño sea reconocida y se le restituya el bien que le pertenece. La función de la inscripción como prueba de la propiedad de un inmueble. Corte Suprema, sentencia de 29 de noviembre de 2018, rol n. ${ }^{\circ}$ 41.935-2017 (CL/ JUR/6642/2018)". Revista Chilena de Derecho Privado. No 32. Santiago.

Alcalde Silva, Jaime (2019b). "Notas para una relectura del sistema de propiedad raíz en el derecho chileno", en Carmen Domínguez Hidalgo (ed.). Estudios sobre propiedady posesión. Perspectiva chilena y latinoamericana. Santiago: ThomsonReuters.

Alcalde Silva, Jaime (2019c). "Notas sobre la prescripción adquisitiva extraordinaria", en Manuel BARRía PAREdes et al. (eds.). Estudios de derecho patrimonial en homenaje al Profesor Daniel Peñailillo Arévalo. Santiago: ThomsonReuters.

Alcalde Silva, Jaime (2018). "La acción contra el injusto detentador del artículo 915 CC. El poseedor a nombre ajeno es el supuesto general de mera tenencia. La ocupación de un bien raíz fiscal sin autorización o concesión de la autoridad respectiva no confiere al ocupante más que una tenencia precaria. Las consecuencias que trae consigo la ampliación jurisprudencial de la legitimación pasiva de la acción reivindicatoria. Una propuesta de reconstrucción del sistema de acciones reales. Corte Suprema, sentencia de 12 de diciembre de 2017, rol n. ${ }^{\circ}$ 12.210-2017. WESTLAW: CL/JUR/7873/". Revista Chilena de Derecho Privado. N. ${ }^{\circ}$ 30. Santiago.

Álvarez GonZÁlez, Humberto (1926). La inscripción no es requisito, garantía ni prueba de la posesión de los bienes raíces. Santiago: Imprenta y Librería Artes y Letras.

Amunátegui Perelló, Carlos (2016). "La doctrina jurídica en Chile. Un breve estudio acerca del surgimiento de la figura del jurista en Chile y la educación universitaria". Revista de Derecho de la Universidad Austral de Chile. Vol. 29, n. ${ }^{\circ}$ 1. Valdivia.

Amunátegui Perelló, Carlos (2019). Código Civil de Chile. Edición anotada, concordada y con fuentes, Valencia: Tirant Lo Blanch.

Barahona Gallardo, Claudio (2016). La teoría de la posesión inscrita en Chile en el siglo XIX (1857-1910), tesis para optar al grado de magíster en Derecho. Santiago: Universidad de Chile. Inédita. 
Barrientos Grandon, Javier (2016). El Código Civil. Su jurisprudencia e historia. Edición crítica, concordada, comentada y anotada, Santiago: ThomsonReuters.

BELlo López, Andrés (1888). Obras completas de don Andrés Bello. Santiago: Imprenta de G. Ramírez. Tomo XII.

Bello López, Andrés (1954). Código Civil de República de Chile. Caracas: Ediciones del Ministerio de Educación. Tomo II.

Bello López, Andrés (1955). Código Civil de República de Chile,, Caracas, Ediciones del Ministerio de Educación. Tomo II.

Bravo Lira, Bernardino (2014). "En busca de los orígenes del Registro Conservatorio en Chile. Bello y el ABGB", en Marco Antonio Sepúlveda Larroucau. Teoría general del derecho registral inmobiliario. Santiago: Metropolitana.

Cavanillas Sánchez, Antonio (2018). "El principio de fe pública registral y la usucapión contra tabulas", Revista de Derecho Inmobiliario. Año 2, N. ${ }^{\circ}$ 1. Santiago.

Coing, Helmut (1996). Derecho privado europeo. (trad.) Antonio Pérez Martín, Madrid: Fundación Cultural del Notariado.

Cuesta Saenz, José María (1984). La acción publiciana. Madrid: Montecorvo.

D’Ors Pérez-Peix, Álvaro (1995). La posesión del espacio. Madrid: Civitas.

Figueroa Yáñez, Gonzalo [coord.] (1996). Repertorio de legislación y jurisprudencia chilenas. Código Civil y leyes complementarias. $3^{\mathrm{a}}$ ed., Santiago: Editorial Jurídica de Chile. Tomo III.

García Goyena, Florencio (1974). Concordancia, motivos y cometarios del Código Civil español, reimpresión de la edición de Madrid de 1852, Zaragoza, Cometa.

Goldenberg Serrano, Juan Luis (2019). "Revisión de los mecanismos de protección de terceros en la regularización de la pequeña propiedad raíz: una primera lectura de la Ley 21.108", en Carmen Domínguez Hidalgo (ed.). Estudios sobre propiedad y posesión. Perspectiva chilena y latinoamericana. Santiago: ThomsonReuters.

GonzÁlez Martínez, Jerónimo (2009). "El principio de publicidad”, en Luis DíezPicazo y Ponce de León. Don Jerónimo González. Madrid: Colegio de Registradores de la Propiedad y Mercantiles de España.

Guzmán Brito, Alejandro (1996). Derecho privado romano. Santiago: Editorial Jurídica de Chile.

Hanisch Espíndola, Hugo (1996). "El mensaje del Código Civil y el concepto de Bello sobre la posesión”. Revista de Estudios Histórico-Jurídicos. XVIII. Valparaíso.

Lasso Gaite, Juan Francisco (1970). Crónica de la codificación española. Madrid: Comisión General de Codificación. Tomo IV.

LARroucau Torres, Jorge (2015). "Acciones reales y estándares de prueba". Ius et Praxis. Vol. 21, n. ${ }^{\circ}$ 2. Talca.

Lira Urouieta, Pedro (1956). "García Goyena y el Código Civil chileno", en $E l$ Código Civil chileno y su época. Santiago: Editorial Jurídica de Chile. 
Mery Berisso, Rafael (1946). "El Código Civil de la República de Chile y los Tribunales de Justicia". Anales de la Universidad de Chile. N. ${ }^{\circ}$ 103. Santiago.

Mewes Bruna, Humberto (1913). La prueba del dominio de los bienes raíces adquiridos por tradición. Valparaíso: Imprenta Royal.

Peñallillo Arévalo, Daniel (2019). Los bienes. La propiedady otros derechos reales. $2^{\mathrm{a}}$ ed. Santiago: ThomsonReuters.

Pino Emhart, Alberto (2019). "Los supuestos de restitución de ganancias ilícitas en el derecho privado chileno". Revista Chilena de Derecho. Vol. 46, n. ' 2. Santiago.

Planitz, Hans (1957). Principios de derecho privado germánico. (trad.) Carlos Melón Infante. Barcelona: Bosch.

Ramos Pazos, Ramón (1985). "Edificación en suelo ajeno sin previo contrato (en torno al artículo 669 del Código Civil)". Revista de Derecho de la Universidad de Concepción. N. ${ }^{\circ}$ 178. Concepción.

Rodríguez-Rosado Martínez-Echeverría, Bruno (2012). "Protección de los terceros adquirentes y de los acreedores en los diversos sistemas transmisivos: un intento de valoración”. Revista Crítica de Derecho Inmobiliario. N. ${ }^{0}$ 733. Madrid.

Rodríguez-Rosado Martínez-EcheverríA, Bruno (2014). "La equivalencia de la escritura a la entrega y el valor de la tradición instrumental”, en Luis DíEzPicazo y Ponce de León (coord.). Estudios jurídicos en homenaje al Profesor José María Miquel. Cizur Menor: Aranzadi/ThomsonReuters. Tomo II.

228 Schiele Manzor, Carolina (2019). "Artículo 894 del Código Civil: ¿prueba de mejor derecho?”, en Carmen Domínguez Hidalgo (ed.). Estudios sobre propiedad y posesión. Perspectiva chilena y latinoamericana. Santiago: ThomsonReuters.

ScIumè, Alberto (1989). "Rivindicazione (diritto intermedio)", en Enciclopedia del Diritto. Milano: Guiffrè. Tomo XLI.

Sepúlveda Larroucau, Marco Antonio (2014). Teoría general del derecho registral inmobiliario. Santiago: Metropolitana.

Trucco Franzani, Humberto (1910). "Teoría de la posesión inscrita, dentro del Código Civil chileno". Revista de Derecho y Jurisprudencia. Vol. VII. Santiago.

UrRutia Anguita, Leopoldo (1934). "Vulgarización sobre la posesión ante el Código Civil chileno". Revista de Derecho y Jurisprudencia. Vol. Xxxi. Santiago.

Veleman, Barry (1995). Andrés Bello y sus libros. Caracas: La Casa de Bello.

Vinogradoff, Paul (1918). "Introduction", in Rudolf Huebner. A Historic of Germanic Private Law. (trad.) Francis Philbrick, Boston, Little, Brown and Company.

ZÁrATE GonzÁlez, Santiago (2019a). "El primer registro chileno sobre hipotecas, censos y naves regulado en el Reglamento de 20 de mayo de 1848". Revista de Estudios Histórico-Jurídicos. N. ${ }^{\circ} 41$. Valparaíso.

ZÁrate GonzÁlez, Santiago (2019b). Tratado de Derecho inmobiliario registral. Santiago: Editorial Metropolitana. 


\section{Jurisprudencia citada}

SCS de 23 de marzo de 2016 (CL/JUR/1830/2016).

SCS de 28 de abril de 2016 (CL/JUR/3060/2016).

SCS de 8 de junio de 2016 (CL/JUR/3789/2016).

SCS de 28 de agosto de 2017 (CL/JUR/5633/2017).

SCS de 31 de enero de 2018 (CL/JUR/521/2018).

SCS de 12 de julio de 2018 (CL/JUR/3768/2018).

SCS de 29 de noviembre de 2018 (CL/JUR/6642/2018). 